\title{
Let's play board game together: How board games benefit child development and learning
}

\author{
Jang, Li-Fen \\ Tzu-Chi University, Taiwan (lifen76209@mail.tcu.edu.tw)
}

Tan, Wai Gie

KidiLand Montessori Preschool, Malaysia (joywaigietan@gmail.com)

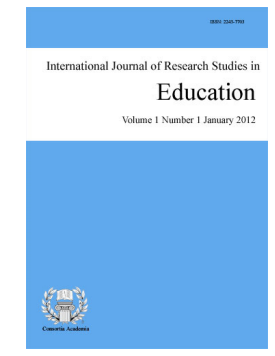

ISSN: 2243-7703 Online ISSN: 2243-7711

Received: 29 January 2022

\section{Abstract}

Play contributes and stimulates learning which helps children to experience their surrounding world and giving meaning to the world in a lifelong process. As research has seen, play influences children's learning as well as in children's development. Play represents significant developmental behaviors in itself and in relation to other developmental domains. Board games play is becoming popular in Malaysia. Parental belief and perception regarding play is important. The study aimed at exploring how Malaysian parents perceive board games play and learning with their children. Through semi-structured interviews, this study investigated 16 Chinese parents' perceptions on board games play and children's learning. These participants were recruited through preschools in Penang, Malaysia. This study found that parents appreciated play and board games play and associated board games play with developmental significance. Parents valued the quality family bonding time which board games could provide. To conclude, parents viewed at play and board games play positively but indicate that both were different from teaching materials. This finding suggested that parents or stakeholders who work with children, could consider using play and board games play as one of the learning methods.

Keywords: play, board game, child development, parental perceptions 


\section{Let's play board game together: How board games benefit child development and learning}

\section{Introduction}

A child's growth and development can be supported and enhanced through play. Play is one the most important aspects in children's life. Play in early years promotes children to explore and master skills, muscles training, mind training and practice social interactions (Schaefer \& Reid, 2001). Play is a spontaneous behavior which begins at infancy. Many studies suggest the importance of play experiences which provides and shares in the stimulation and learning for infants and young children during play. Play contributes and stimulates learning which helps children to experience their surrounding world and giving meaning to the world in a lifelong process. As research has seen, play influences children's learning as well as in children's development (Ginsburg, 2007; Miller \& Almon, 2009; Nicolopoulou, 2010). For example, Ginsburg (2007) indicated that children learn to communicate and relate to the world at young age through games. Nicolopoulou (2010) also stated play promotes socioemotional abilities, namely ability and children's interest to cooperate and understand others emotionally in their early years. Play helps children in promoting different developmental domains, such as language, social and emotional development.

In a lot of existing researches, we studied play based on different theorists' definition of play. For example, Vygotsky described play as "sociodramatic or make-believe play" (Bodrova \& Leong, 2015). In this kind of play, children are role-playing in the imagined environments which abide certain regulations restricted to the roles (Bodrova \& Leong, 2015). By continue to give meaning to the roles or objects, children can understand more complex symbol systems which help them in later school years. While in Piaget's work, he viewed play as the children's control and planned behaviors executed in their world. Children get to practice their self-control through play (Henricks, 2014).

Apart from reviewing "play" from theorists' points of view, parents' belief about play also influence play with their children. Haight, Parke, and Black (1997) showed that there is a relationship between parents' perception on play and parental support on play. When parents emphasized the importance of play, they tend to play more with their preschool children. Moreover, as Fogle and Mendez (2006) investigated, when parents think of play positively, they see the important role of play in preschool children's development especially cognition and social development. However, parent's cultural belief affects how parents view of play. For example, Parmar, Harkness, and Super (2004) found that Asian parents did not appreciate play for their preschoolers and provided lesser play time and play types for their children.

Board games have becoming more popular among the play methods. At the same times, board games have become more complex and more strategy-inquired instead of luck and it has become more mainstream play (Booth, 2015). In another words, board games have gained its place in mainstream players instead of only available to the subgroup geek players. Looking at board games history, board games develop from traditional board games (like chess sets, Draught or folk games) to mass-market board games (like Monopoly, Scrabble or party games) and hobby games (like war-gaming, card games) (Sung \& Ching, 2012; Woods, 2012). In this transformation, there are a lot of different elements being featured in the board games and researchers may find the elements that is helpful in children's development.

As there are limited researches done on board game plays usage at home, the purpose of this study explored the current perceptions of Malaysian parents on play and board games play. In addition, the research aimed at describing the experiences and involvements of Malaysian parents engaged in the family board games play sessions. Moreover, this study aimed at studying factors which influence parents to introduce board games at home to look at the reasons which parents' value board games play. 
Let's play board game together: How board games benefit child development and learning

1.1 Research Questions

$\rightarrow \quad$ What does play mean to Malaysian parents? How is these activities benefit their children?

$>\quad$ What does Malaysian parents understand about board games? What, if any, are the benefits and drawbacks of board games play?

\section{Literature Review}

\subsection{Board Game and Learning Outcomes}

Play serves as a tool for children to learn, and the benefit of play is clearly recorded in researches. According to Chou (2017), board games were very beneficial when introducing to children at early learning stages. Board games mechanism in required steps to win, turns taking, ultimate winner and working with other players, helped children significantly in their developments and characters building like perseverance and be patience (Chou, 2017).

Cognitive development: Different types of board games yield different outcomes. For instance, competitive board games motivate players towards success through strategies formation and practice decision making skills (Bay-Hinitz et al., 1994).

Mathematics: Board game play affects numeracy development, instructional practices during board game play, and connecting home and school. Researchers also found that small group of preschool children who were aged from three to five years old improved in their numerical skills like counting and identifying the numbers after playing numbers board games (Ramani, Siegler \& Hitti, 2012). A primary area of early mathematical development is number sense. Number sense involves an understanding of the meaning and representation of numbers as well as relationships among numbers, and it includes counting, numerical comparisons, and verbal and nonverbal addition and subtraction. A pre-assessment of children's numeracy skills showed that some students could not differentiate larger quantities from smaller quantities, even when they could count from 1-10. Yet, board gameplay engaged kindergartners in mathematical activities, improved verbal counting, helped the accurate identification of numbers, and enabled participants to compare numeral quantities (Hendrix et al., 2018).

Language \& literacy development: Board games come with rules and instructions, these rules are included in the rulebooks. Sato and de Haan (2016) stated that game players learn to read and comprehend the steps in the rulebooks so that they understood how the games were played. In Malaysia, board game was used as a teaching tool in grammar lesson, and the research results showed that several positive outcomes that can be seen after several activities have been carried out in the classrooms. By using board game as the supplement to textbooks, the students are motivated to learn grammar as they believe that board game is an interesting and useful method to be used in the classrooms (Paris \& Yussof, 2012).

Social development: To learn to form certain strategies and to learn how to make appropriate decisions to win the games, requires our children to observe, learn and communicate with their parents. Bandura's social learning theory proposed that children will first observe people around them and process their behavior (Bandura, 1977). Then children will imitate the certain behavior and later reproduce the certain behavior which fit the environment. In competitive board games, children will observe how their parents work towards winning the game and children will seek for their parents' teaching in winning the games. In the teaching process, parents and children get to communicate and learning from one another. According to Nicholson (2008), the board games nowadays have evolved more than just "roll-and-move". The later version of board games is focusing on involving all players to work towards a goal, players can play simultaneously instead of waiting for their turns and there are many ways to win the games (Nicholson, 2008). Furthermore, players as young as children also get 
to practice patience and respect while waiting for their turns (Chou, 2017). Chou (2017) also indicate that board games offered players to interact in the game process no matter of ages and skills difference. Children also learnt to accept failure due to the recurrent failures which might appeared in board games play where there was only one ultimate winner. In the process of game playing, players were able to share tips and techniques, guide the less experienced players, to motivate the game playing (Chou, 2017). Therefore, playing board game also help children to develop their social development, such as, taking turn and perspective taking, and deal with pressure.

Learning and curriculum: Board games have been included as one of the teaching methods for numerous teaching areas, for example learning grammar rules (Paris \& Yussof, 2012), increasing numeracy skills (Wang \& Hung, 2010), improve aesthetic experience (Chou, 2017), promoting healthy lifestyle (Bartfay \& Bartfay, 1994) and so on. Bartfay and Bartfay (1994) incorporated board games to promote healthy lifestyle among nine to twelve years old school children found that board games were able to let school children learnt more about their health, their food intake and lifestyle risk. They commented that board games were the most appropriate tool to use for younger children to learn about cause and effect. At the same time, Mostowfi, Mamaghani and Khorramar (2016) invited 20 primary school children to design a board games which was related to environmental issue such as recycling. While Berge, Telke, Tate and Trofholz (2019) utilized board game as a tool to observe family functional factors, family interaction, family relationship quality and parenting behaviors during the board games play at home. In addition, educational board games have been used in some areas of medical and health professionals' training and have been shown to enhance learners' knowledge, enjoyment and interest in the subject (Whittam, \& Chow, 2017).

\subsection{Board Game}

Board games have becoming more popular among the play methods. At the same times, board games have become more complex and more strategy-inquired instead of luck and it has become more mainstream play (Booth, 2015). In another words, board games have gained its place in mainstream players instead of only available to the subgroup geek players. Looking at board games history, board games develop from traditional board games (like chess sets, draught or folk games) to mass-market board games (like Monopoly, Scrabble or party games) and hobby games (like war-gaming, card games) (Woods, 2012). In this transformation, there are a lot of different elements being featured in the board games and researchers may find the elements that is helpful in children's development.

As Schaefar and Reid (2001) brought up, in the last decades, researchers have studied a lot of the effects of board games on the therapeutic use in children. In addition, a lot of studies have done to investigate the learning effects of board games in classroom setting. Many researches have shown how board games increased classroom literacy in math, numbers, colors and how peer's relationship influenced through board games play (Chou, 2017; Paris \& Yussof, 2013; Wang \& Hung, 2010). Most of the researches have investigated how board games have their influences in classroom environment but not at home. At the same time, the mushrooming of board games usage in the last decades indicates that more exposure of board games play in childhood, but there is very limited researches have done on how parents perceive board games play. Therefore, this research would like to work in this direction, to understand Malaysian parental belief on play, development, and perceptions on board games play.

Board games can be played on tabletop with counters and hardboards with printing. But in larger concept, card games can be also included in the group of board games (Nicholson, 2008). Berland and Lee (2011) stated that board game play is an entertaining activity which can be played with friends or within family and there are certain rules to follow. Board game serves as a tool for social activity where it can involve all the players for a certain time period (Nicholson, 2008). Chou (2017) also suggested that board games act as a tool where players are all interrelated to one another regardless of their backgrounds.

Types of Board Games - Board games can be categorized based on themes, mechanics, or based on the 
components in the game (Chen, 2017). According to Hsi (2017), the most common way to categorize board games is based on Board Game Geek, a website which collects players' review and incorporate most of the board games. In the table of contents in Board Game Geek website (2018), there are several categorization methods which based on the board games' activities, components, skills acquired in the games or based on themes. It can also be simply categorized its types, such as party games, abstract strategy games, children's games, or war games. While Hsi (2017) analyzed the category on Board Game Geek and categorized the board games into eight groups, which are Abstract Games, Customizable Games, Children's Games, Family Games, Party Games, Strategy Games, Thematic Games and War Games.

Adult Role in Board Games - Board game not only offer valuable opportunities to practice math skills at children's own pace, but also allow children to deal with attention, eye-hand coordination and cognitive development. Bennett, Wood, and Rogers (1997) also found that during teacher and children interaction in the games, teachers' role of applying playing materials, tips and techniques help children learn better and achieve higher result in learning. Therefore, it is advisable to include play and board games play in teachers' curriculum to achieve higher learning results.

In another study, adults acted as individualized supporter to children in which the adults changed their roles according to children's needs (Ramani et al., 2012). When children were poorer in performing their play, adults gave more support while children were playing smoothly on their own, adults observed and gave only general prompts.

Scaffolding represents the way in which parents guide children's learning during a goal oriented task by offering support at different levels depending on the child's current developmental level and learning needs. When a child's play is scaffolded by an adult/parent, the child is experiencing and learning about positive social interactions, active engagement, adaptability, and joy. In conclusion, play is essential in children's life. This literature review discussed how play is supported as the vehicle in times for children's experimentation and exploration in early developmental domains.

\section{Methodology}

The study investigated the perceptions of Malaysian parents regarding play and how board game benefits children's development when playing with their children. The study discussed the research design, selection of participants, procedures, trustworthiness, data collection, data analysis and summary.

\subsection{Research Design}

By using a qualitative research method of inquiry, this research discovered how Malaysian parents perceive board games play by using interviews. One of the common data collection tools in qualitative research is interviewing. Therefore, in this study, interviews were used to understand the current phenomena extensively (Jamshed, 2014). Due to its benefit in offering in-depth understanding about the arisen issue board games play in Malaysia, and semi-structured interview were employed in this study. In semi-structured interview, open-ended questions were set prior to the interviews as a guide in the interviews. With the guidance from the pre-set questions, interviewers can collect data systematically and wholesomely, and able to stay at the focus point (Jamshed, 2014).

\subsection{Selection of Participants}

The invitation of letters was sent to parents and ex-parents of preschools located in Penang, Malaysia. The chosen of preschools applied convenience sampling, as current research looked for participants who have experiences in playing board games with children and who can converse in English. The first email sent out contain a short explanation of the purpose of research and some relevance information about this study. 80 emails were sent out and 22 parents expressed their interest. However, there were only 16 parents who met the 
criteria. After interviews time and date were set, the researcher made appointment for face-to-face interview to meet up at places which were most convenience to the participants, which were participants' houses, preschool and researcher's house. Participants' consent forms and details of the study have explained to our participants and sought for their approval for audio recording during the interviews. The informed consent forms indicated that participants' confidential would be protected by anonymous in reporting the data and ensured that participants' information would not be published.

The current research had recruited 16 participants who was experienced in board games play and who could converse in English. All participants stayed in Penang Island, Malaysia. All participants were in the age range of 36 to 48 years old. All participants had at least one child from the age of 4 to 12. Experienced board game play parents were those who have played or are playing board games with their children at least 5 times.

\subsection{Procedures}

The data collection tool for current study utilized face-to-face, semi-structured interviews which may last for 45 minutes to one hour. After meeting up at the convenience places with participants, prior to interviews, researcher built rapport and credibility with the participants by introduction and brief conversation. The interviews started when participants were fully understanding about the study, signed the informed consent forms and agreed with the audio recording. The interview schedule contained of 12 open-ended questions which aims at exploring parents' perceptions regarding play and board games play. Five questions were asking how parents perceive play and the later seven questions investigated parental perceptions about board games play. The areas to inspect are usually asked in a few researches (Parmar et al., 2004; Fogle \& Mendez, 2006; Breathnach, 2017):

$>$ Definition and importance of play

$>\quad$ Play and child's development

$>$ Definition and importance of board games play

$>$ Board games play and child's development

$>$ Parental involvement and experiences (enjoyment) about board games play

Trustworthiness - This study looked at trustworthiness which incorporate of four criteria: credibility, transferability, and dependability (Guba, 1981). Firstly, credibility is achieved when study presents accurate analysis or investigations not only on participants but also to people who have mutual backgrounds and that these people can identify the analysis directly (Krefting, 1991). This study employed peer examination method to increase the credibility. Qualified peers who have educational research background to check the interviewing questions and transcriptions textual data. Interview techniques like reframing had been used to increase credibility as participants may answer what was preferred but not their personal thoughts. Secondly, transferability is met when the analysis of study not only fit the research site but also similar contexts out of research site (Guba, 1981). The purposive sample employed in the current study was to increase transferability. Thirdly, the dependability in data analysis would be met when the researcher and participants' variability are taking into considerations, for example, participants' tiredness. The current research employed code-recode procedure to increase dependability. When the audio recordings were transcribed, the textual data have checked for twice. The textual data were sent to all participants to check if their data were transcript correctly and whether the data were transcript into their original meanings. All the participants confirmed that the transcript textual data were their original meanings.

\subsection{Data Collection}

Semi-structured interviews were conducted with parents who have related experiences of playing board games. The data collected was manually transcribe via Microsoft Office 365 Word software. All participants met 
up one time with researcher one-on-one and face-to-face. After analysis of interview data was completed, there were four participants which researcher called up on phone in order to obtain possible clarity and additional interviewees data. Afterwards, parents have been assigned an individual coding number in order to ensure anonymity. Upon completion of this study, recordings will be erased from the researcher's laptop and transcriptions shredded in order to comply with the tenants of research confidentiality.

\subsection{Data Analysis}

The following procedures have been used to analyse the data. Step 1: After finish transcribing the interviews, researcher first looked through all the textual data. It was to get a general idea of all the collected data. At the same time, researcher took note down her thoughts in the margin, this included all the ideas, concepts or what Creswell (2014) suggesting, the "underlying meaning".

Step 2: The second step was coding. Researcher looked for shared ideas or topics in the textual data. Then researcher grouped the similar topics and coded the topics by using terms or vivo terms (Creswell, 2014). The textual data has been chunked into different codes. After that, the textual data which belong to the same code has been moved under one new document page and has been named under the code (term or vivo term).

Step 3: The next step was categorizing the codes which have the same themes. The themes were developed from different viewpoints which are supported by literature review and evidence (Breathnach, 2017). Then the themes were discussed and analysed later in finding section.

\section{Result}

In this study, semi-structured interviews were conducted with parents who have related experiences in playing board games. Using explanatory framework, researcher started with coding and developing themes for the text data, the transcript. The themes were developed when looking at how participants perceive play and board game play in Malaysia context. In this section, the demographic data of the participants were discussed and then followed by the emerged themes after analysing the interviews data.

\subsection{Demographic of the Sample}

In this study, there were 16 participants who were parents to at least one child aged between five to twelve years old and had at least five times board games play experiences with their children. All participants were Chinese and stayed in Penang Island, Malaysia. All participants were in the age range of 36 to 48 years old. Two of the interviewees had finished their diplomas and 11 of them had their bachelor's degree. Another three of them had master's degree. Six participants had single child, seven participants had two children and three participants were parents to three children.

\subsection{Play makes learning easy}

When we talked about the benefits of play, participants shared that the learning value in play was very much appreciated. They commented that play attracted children's focus easily and it made learning easier through play.

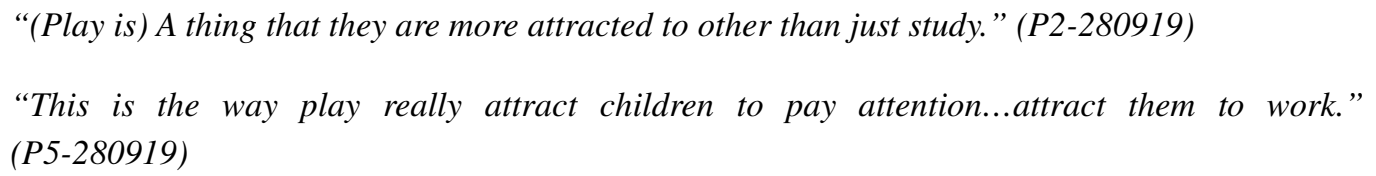

Children were easily attracted to play, and participants shared that it would be good if children can learn and play at the same times. The "learn through play" method were mentioned. Parents emphasized on the learning 
outcomes of play, stressed that children should gain something out of play.

“...teach it through a game. So I think there are a lot of ways that you can incorporate playing into life, you also can teach skills like: strategy thinking, critical thinking, it's all part of how you deliver or how you structure the game.” (P4-280919)

my children.” (P9-300919)

“I learned (that) even simple games can actually teach you a lot of things.” (P16-051019)

"When you include learning into play, the child doesn't realize that is, learning. But the child looks at it as a play and the child play and learn at the same time. Overall, the child gains.” (P16-051019)

\subsection{Play as children's "scaffolding"}

Parents indicated that play not only tickle the interest of learning, play was also able to "scaffold" children to explore more and develop more than their usual learning.

"I think they learned through the play, especially those like you know not academic or book related, they pick up even faster.” (P1-240919)

"Play is a tool that helps you explore more. You learn a lot of things through play and all these help with the child's development. When you play, you absorb the knowledge." (P3-280919)

Parents viewed highly on the learning value of play. Not only play attracted children to work and learning, play also "scaffold" children that they were able to achieve higher levels than they were actually have expected.

\subsection{Play and various developmental domains}

Academic learning. Participants shared that they observed their children were learnt through play and some of the aspects were related to academic learning. The examples were language, linguistic, mathematical skills, and reading skills.

"For my son, he doesn't really read very well yet, but his vocab is quite rich. And he gains this all through play we have at home.” (P1-240919)

"It is also helping in brain development and learning ability like math counting, reading." (P14-021019)

"How she gives an instruction like when we play blocks... giving instruction became clearer to her." (P15-051019)

Play benefits related to child's development - Other than the academic learning, parents also commented that play enhanced other child's developments too, like cognitive development, social development, physical \& motor development, creativity and character building. The character building mentioned by parents included good social etiquette and good manners.

Cognitive development:

"(During play) explain to them this is the rules and these are the limits, then they can learn how to control themselves better." (P1-240919)

“...strategy thinking, critical thinking, it's all part of how you deliver or how you structure the game.” (P4-280919)

62 Consortia Academia Publishing (A partner of Network of Professional Researchers and Educators) 
Let's play board game together: How board games benefit child development and learning

"learning, especially the critical thinking. Play makes them curios. Curiosity being lure up when they play. The curiosity will slowly lead to imagination.” (P5-280919)

"It practices their logical thinking of cause and effect." (P5-280919)

"They learn non-academic skill development, like planning and problem-solving skills." (P7-280919)

Creativity:

"They learn to do things in another way after exploring and come up with another way, like the creativity.” (P1-240919)

"It develops creativity, in a sense that sometimes you play on your own, you have to create, like, think of like a scenario.” (P4-280919)

"If they are playing alone, they can maybe stimulate their mind, make them more creative in looking at things differently.” (P10-300919)

Social development:

"Play is actually teaching them...the interaction part, the give and take, and how to interact with each other.” (P2-280919)

"...how to be considerate towards one another and how basically how they express and communicate with each other, the social part. Especially the EQ skills, how to bond each other, how they fight then be friends again. EQ (also involves) how you communicate with people." (P2-280919)

"If you play with friends, then yes, there's a lot of social interaction and then you have to learn to cooperate as well sometimes it's like a team play. Then then you need to learn cooperation." (P4-280919)

"Of course, is teamwork, and learning to cope with losses, because ultimately, sometimes play there'll be one winner and one loser.” (P10-300919)

"Certain games were involving more people, then they will learn how to play as a team. How to play together and not just by themselves.” (P11-300919)

"Socially, when they get to know other friends around (their) neighbourhood. The social interaction shapes you and prepare you when you are a little older and you go to school." (P11-300919)

Physical and motor development:

“They learn to twist and practice their fine motor skill.” (P5-280919)

“These games benefit the kids from response and also eye-hand coordination." (P8-290919)

"The more they do it, sometimes they get faster than they are better with their motor skills." (P10-300919)

“(Play) develops gross motor and fine motor skills, bilateral coordination, and then achieving milestones.” (P16-051019)

"You also improve your gross motor skills or fine motor skills once again. And by playing, you 
also enhance your immunity, you make yourself healthier.” (P16-051019)

Participants viewed highly on the benefits of play brings and they were able to mention a lot of benefits which they observed in the play sessions. The benefits were categorised into academic learning and other child's development. Participants shared that they observed play enhanced in various child's development, such as language, physical \& motor, social, cognitive, and creativity.

\subsection{Parental roles in the board games play}

Child-led play was mostly mentioned in play, but not in board games play. Being very different from play, in board games play, most of the parents reported of the role of guidance and facilitator in the board games play. In board games play, the mechanism was different from the play. For example, in board games play, certain steps and rules were needed to obey and there was the ultimate solely winner where other parties lose. Parents reported on the role of moderators too, to moderate and regulate children's emotion on winning and losing. Parents also observed their roles as scaffolding as they kept challenging their children to move forward from one level to another.

"Occasionally, I let him win just to let him feel positive. And explain to him the techniques and strategy on winning." (P2-280919)

"To explain the steps, encourage the children to continue to play. To teach techniques and skills, to provide tips sometimes.” (P5-280919)

"Sometimes when he loses, he will be very upset, do not want to pay anymore. I will just attend to him emotion first; we talk about the feelings. Then we discuss the technique and strategy to win and encourage him to play some more." (P9-300919)

"As an encourager, I am the one finding good games, getting hints and tips, encouraging them not to give up." (P10-300919)

"My role usually in a board game play is to give few levels of difficulty for them to solve or distributes a few challenges to them in the board games play. The intention of doing so is to develop the child strategizing and problem-solving skills.” (P14-011019)

"To involve the challenging level so that we are able to keep up with the child's development." (P15-051019)

"Some board games concentrate on certain areas, be it drawing or math or language." (P4-280919)

"Monopoly help her mathematic. My child also learns about occupation trough playing card games, the Happy family.” (P8-290919)

"More obvious on the calculating. Language and general knowledge too if the games involve some understanding of certain vocab. It also helped them to be able to articulate better. Especially when they learn to read rules books and some games include Geography knowledge." (P12-011019)

"It allows the child to be able to have longer focus attention span.” (P14-021019)

\subsection{Board game benefits to child's development}

Interviewees also shared how board games play helped in enhancing different child's development, especially on the cognitive development, social development, character building and creativity. 
Let's play board game together: How board games benefit child development and learning

Social-emotional development. Participants commented that there are other players in board games and through board games play, children learn to interact, communicate, obey rules, be patience and wait for their turns, expressing oneself, learn to deal with losing and winning. These aspects are all helpful in enhancing children's social development. Children also learn to express themselves and negotiate with others in board games. Participants shared that board games are all come with rules, therefore children practice following rules in play time in order to win the game. Furthermore, parents shared that children practiced turns taking in board games as there are other player(s) involved, which will later lead to practice patience. In some cooperative board games, children learn to collaborate and work together as a team. Due to board games criteria of either winning the game or losing the game, children get to learn how to deal with winning and losing. The acceptance of winning and losing is part of the emotional development where children learn. Some parents shared that children at young age want to win all the times but reluctant to accept losing. Therefore, learn to accept winning or losing is a big task for the children. Parents practiced emotional regulation with their children no matter winning or losing.

"My child will get to know how to obey with rules of the games... and wait for their turn with patience" (P1-240919)

"Social development on waiting for his turn, congratulate the winner. And he takes win or lose better, emotionally.” (P1-240919)

"Social skill will improve as they need to look for other playmates to play together, teamwork during game time. They will need to communicate in the process, and they learn to express themselves." (P5-280919)

"Child learned about discipline, follow rules, social with playmate, teamwork as well as accepting losing result.” (P8-290919)

"We have fun all the time no matter is win or lose. We share our feeling to each other. They learn to communicate; they learn to express themselves and learn to negotiate with others." (P9-300919)

"It helped them to learn about social etiquette, patience, expressive, applying the skill of observation. Social etiquette are they can learn turns taking, not getting angry when losing, learn about losing, learn to wait patiently and not to be arrogant when winning.” (P12-011019)

"They learn to accept failure. to try. To not to be too proud over winning, to be polite and patience.” (P12-011019)

Language Development.

Playing board allowed children to express the ideas, and communicate with their player, or some of the board games include the element and rule that require children to express and communicate with others. Moreover, children need to use their language to express how they felt.

"Board game play also enhances the interaction with people during game time. And most important is, two-way communication is included during game time." (P6-280919)

"Social interaction will be involved too, like interaction with other players, how to communicate nicely and most importantly how to lose graciously.” (P10-300919)

"A way for them to express themselves and for us to express ourselves...Definitely they will be like, speaking out, expressing themselves, like displeasure... communicate with one another" (P2-280919) 
"Communications and teamwork are also slowly developed. When knowing what the whole game like, the process of having fun, emotional control of not only embrace winning but also knowing why losing.” (P3-280919)

Cognitive development and math.

Via board games play, children get to work on their logical thinking, strategic planning and problem-solving skills, which are all prominent aspects in cognitive development.

"Cognitive definitely, as in the board games probably they need to strategize...Encourage critical thinking when they strategize on how to win." (P2-280919)

"It exposes them to various strategic thinking and requires them to follow rules. Some games encourage participants to think critically and logical reasoning." (P4-280919)

“He will learn to think what I should do for the next step, learn to strategize.” (P9-300919)

"For example, when we play UNO stacks, it involves problem solving thinking as to take out which piece so that the pillar is still stable." (P14-021019)

"Card games like happy family, could let my child practise logical thinking and strategize as they try to read and guess the other players' cards to take the cards they wanted.” (P14-021019)

Parents also observed that perseverance was practiced in the process of board games play. Children observed how other players play and they kept trying out in order to master the skills and techniques and later lead to winning.

"But then when he didn't give up and keep learning from experience of game play, he started to get better and feel happy with his own achievement." (P1-240919)

Some parents mentioned that children utilized math skills when they play board games.

“She learns about general knowledge and math like numbers and calculation." (P6-280919)

"When tossing the dice, they learn counting. On monopoly board game, they focus on cash flow.

They learn the concept of money and always keep cash on hand.” (P13-011019)

"For example, snake and ladders, it is not just about reaching from one to 100, it's also counting that is involved over there. You can also include calculations, additions." (P16-051019)

Cheung and McBride (2017) suggested that small group activities seem to be an effective way to promote early math skills. The small group format may also have been effective because children learned from each other while playing the game. Children may have learned how to play the game, to identify the numbers on the board, and how to count while watching their peers move, as well as on their own turns.

\section{Creativity.}

Parents observed that creativity is being cultivate in board games. In board game Charades, children need to act out creatively to get the correct answers. The creativity can be also been practiced in the board game Pictionary. Sometimes children choose to come out with new rules or new play steps instead of the original ones

“Creativity, to try to solve problem or counter his opponent during game play.” (P1-240919)

“Creativity, plotting or thinking out of the box.” (P2-280919)

"Some games encourage participants to think out of the box or to think critically." (P4-280919) 
Let's play board game together: How board games benefit child development and learning

“Creativity also improve especially when they create own games with own rules." (P5-280919)

"Creativity for sure, I would say most of the time, my daughter take initiative to play in creative way, she comes out with new rules, new way of playing." (P6-280919)

"When you wish to win, you will find way to get to your goal, whether from experience or observation, some elements of creativity definitely exist. They also love to create rules or own variations to make the game more interesting." (P12-011019)

Play helped with children's various developmental domains. The different developmental domains were stressed on the social-emotional, cognitive, character building and creativity.

In conclusion, the current study interviewed 16 participants who were experienced board games play parents in Penang, Malaysia to find out their perceptions of play and board games play. 16 parents viewed at play positively and most parents related play with fun activities. Participants indicated that play shall begin from the very beginning of childhood. Participants mentioned a few benefits of play which were play provided interaction time for parent-child relationship, play helps in academic learning and various children developments. When participants shared about board games play, they viewed board games which were played indoor. Several benefits of board games were mentioned, such as enabling parents to witness children's progress in the process board games, provided family bonding time create learning opportunity. Parents also related board games play with various learning domains. On the other hands, parents were concerned on a few elements in board games play, for example, the lengthy time, the high cost, choosing on the age-appropriate games and the limited choices available in Malaysia.

\section{Discussion and Implications}

\subsection{Discussion}

Overall, current study found out that play and board games play bring a lot of benefits to children. Play and board games served as vehicles for developing children from different developmental domains and both also tickles children's interest to work unknowingly. This finding suggested that parents or stakeholders who work with children, could consider using play and board games play as one of the learning methods. The 'learn through play' pedagogy should continue to be incorporate in teaching especially with younger children who preferred hands-on experience. The learning opportunity in play and board games play could be varied, it could be enhancing children's developments, characters building or practice academic learning.

During the board game, parents' involvements were offered for parent to engage in their children's learning and behavior modification with children. In Kennedy et al. (2017) research, they studied how board games helped schooling children to communicate in the family. One of the results reported was family members reported that they felt being connected through board games play. Family members shared feelings, felt being involved, being supported and knew one another more through board games play (Kennedy et al., 2017). At the same time, researcher found the similar findings in this study. Parents shared that board games offered quality bonding time for the family. Parents and family should continue to introduce board game splay in their family time to enhance quality parent-child relationship. The findings in current study also encourage more parent involvement and quality play or bonding time with children via play and board games play.

\subsection{Implication}

Encouraging the parent-children activities. Parents took not only their own beliefs, expectations, and concerns into the perceptions of play, but they also appreciated the contribution of playing behaviors and the tools, such as board game. However, after studying their perceptions about play and board games play, parents appreciated the developmental significance of play and board games play but not viewing both as teaching 
materials.

In parents' education, there shall be a section of introducing parents on how to utilize board games play and play in their teaching with children. Not only as teaching materials, parents may also look at how board games could incorporate into their family fun time, bonding time, and even utilize board games as a tool for knowing one another better. As Sherwood and Reifel (2010) indicated that stakeholders viewed as a not-so-serious work or invaluable learning styles when comparing play to adult-led, structured academic works. Through parents' education, parents could learn ways to incorporate play and board games instead of adult-led activities.

Play and board games play could be the vehicle for socializing and interacting, especially with board games play which included more than one player. The socializing elements in board games play enable players to share their experience, feelings, thoughts and common interests. Therefore, board games play worked very well as a lubricant to quality bonding time. Parents and family should continue to introduce board game play in their family time. Adult also provide scaffolding when play with children. Children play board game and learn through tips, and parents also provided with guidance and encouragement during the playing session, and in addition, the quality time with children.

Designing teachers' curriculum. The results of this research found out the play and board game play benefit children's learning and development. Play and learning is not enemy and should be seen as a partner. Different board games have been included as one of the teaching methods for numerous teaching areas, for example learning languages, increasing numeracy skills, improve aesthetic experiences, promoting healthy lifestyle and many more. As learning outcomes of board games had been discussed in current study, the findings suggested that teachers might continue to incorporate board games in designing teachers' curriculum or use it as teaching materials. Teachers or parents may play with children and teachers are able to use this as the materials for parent-child activities. For the implication of educators, we can invite parent to play board games with children in parent-children activities, or provide the ideas for parents to learn what board game benefits children's learning and how board games affect children's development. After finished the board games activities, the teacher may provide the chances to introduce parents what kinds of development or skills that children are employed. Therefore, parents' participation in play activities is one of the most powerful ways that parents influence their children's development or learning. Such participation may be direct, with parents providing opportunities for their children's guided participation or experiences of scaffoldings.

\subsection{Recommendations for Further Study}

Based on this study, the following recommendations for future research are as follows:

$>\quad$ Current study only managed to recruit Chinese participants in one state. In future, more studies could be done in recruiting other races to represent the population in order to generalize the study to Malaysian parents. Furthermore, future studies could be done to include observational method in studying parental perception. The observational method may offer researcher a chance to observe things, thoughts and perceptions that participants might be unwilling to discuss in an interview. Moreover, observation gives the researcher an opportunity to see things that routinely escape awareness of the participants.

$>\quad$ Future researches could also work in introducing variety types of board games to parents as there were very limited board games types which were popular among the recruited participants. Most of the board games mentioned were classic board games and therefore the drawbacks like lengthy time, complex steps were mentioned. As Nicholson (2008) mentioned, the board games nowadays have evolved more than just "roll-and-move". The later version of board games is focusing on involving all players to work towards a goal, players can play simultaneously instead of waiting for their turns and there are many ways to win the games. 


\subsection{Limitations of current study}

There were several limitations of current study that should be addressed. First of all, the participants were recruited through convenience sampling in a state of Malaysia, Penang. The results of current study might be inappropriate to generalize the findings to general populations of Malaysia parents. Secondly, parental cultural belief might affect how they perceive play as what Parmar, et al. (2004) found out which indicated that Asian parents did not appreciate play for their pre-schoolers and provided lesser play time and play types for their children. The present study had recruited all participants who were Chinese while Malaysia is a multiracial country with more than five ethnic groups. The cultural belief of parents might influence how they appreciate play and board games play. Thirdly, the parental perception was studied through interview method where participants self-described of their own experience and perception about play and board games play. The bias might appear as the data was self-reported. Self-reported data might be answered to the favors of researcher in the study but not what the participant's real perceptions.

\subsection{Conclusion}

Play is a natural activity as well as a developmentally significant phenomenon for young children. The importance of play has been addressed in many research studies. On the other hand, the evidences about the effects of play deprivation on child development were also presented in many studies. Play is a cherished part of childhood that offers children important developmental benefits and parents the opportunity to fully engage with their children. Play benefits children's development and learning at a very early age through childhood. Play is young children's most familiar and comfortable tools for engaging the world, furthermore, play is a useful measurement for understanding the development progress. In addition, playing board game is used as a scaffolding method for parents or peers to help children to learn and benefit their learning. Play is a child's safe zone and parents can help facilitate this area of developmental growth through active engagement. The parents provide the child with a new way of playing with the same object or involving the object in a new style of play. Parental engagement with children are also encouraged for parent to spend quality time with children. More broadly, providing parents with training and access to board game or parent-children activities would likely strengthen children's development and skills.

\section{References}

Bandura, A. (1977). Social learning theory. Prentice Hall.

Bartfay, W. J., \& Bartfay, E. (1994). Promoting health in schools through a board game. Western Journal of Nursing Research, 16(4), 438-446. https://doi.org/10.1177/019394599401600408

Bay-Hinitz, A. K., Peterson, R. F., \& Quilitch, H. R. (1994). Cooperative games: A way to modify aggressive and cooperative behaviours in young children. Journal of Applied Behaviour Analysis, 27(3), 435-446. https://doi.org/10.1901/jaba.1994.27-435

Berge, J. M., Telke, S., Tate, A., \& Trofholz, A. (2019). Utilizing a board game to measure family/parenting factors and childhood obesity risk. Journal of Nutrition Education and Behavior, 51(4), 419-431. https://doi.org/10.1016/j.jneb.2018.12.008

Berland, M., \& Lee, V. R. (2011). Collaborative strategic board games as a site for distributed computational thinking. International Journal of Game-Based Learning, 1(2), 65-81. https://doi.org/10.4018/ijgbl.2011040105

Bodrova, E., \& Leong, D. J. (2015). Vygotskian and post-Vygotskian views on children's play. American Journal of Play, 7(3), 371-388.

Booth, P. (2015). Game play: paratextuality in contemporary board games. Bloomsbury.

Breathnach, H., Danby, S., \& O'Gorman, L. (2017). ‘Are you working or playing?' Investigating young children's perspectives of classroom activities. International Journal of Early Years Education, 25(4), 439-454. https://doi.org/10.1080/09669760.2017.1316241 
Chen, R. W. (2017). The parent-child relationship promotion project adopted the board game as the facilitating material: Design, development, and its benefit investigation. https://ndltd.ncl.edu.tw/cgi-bin/gs32/gsweb/cgi/ccd=vUcL9w/fulltextdeclare

Cheung, S. K., \& McBride, C. (2017). Effectiveness of parent-child number board game playing in promoting Chinese kindergarteners' numeracy skills and mathematics interest. Early Education \& Development, 28(5), 572-589. https://doi.org/10.1080/10409289.2016.1258932

Chou, M. J. (2017). Board games play matters: A rethinking on children's aesthetic experience and interpersonal understanding. Eurasia Journal of Mathematics, Science and Technology Education, 13(6), 2405-2421.

Creswell, J. W. (2014). Research design: Qualitative, quantitative, and mixed methods approaches (4 ${ }^{\text {th }} \mathrm{ed}$.). SAGE Publications.

Fogle, L. \& Mendez, J. L. (2006). Assessing the play beliefs of African American mothers with preschool children. Early Childhood Research Quarterly, 21, 507-518. https://doi.org/10.1016/j.ecresq.2006.08.002

Ginsburg, K. R. (2007). The importance of play in promoting healthy child development and maintaining strong parent-child bonds. Pediatrics, 119(1), 182-191. https://doi.org/10.1542/peds.2006-2697

Guba, E. G. (1981). Criteria for assessing the trustworthiness of naturalistic inquiries. Educational Resources Information Center Annual Review Paper, 29, 75-91.

Haight, W. L., Parke, R. D., \& Black, J. E. (1997). Mothers' and fathers' beliefs about and spontaneous participation in their toddlers' pretend play. Merrill-Palmer Quarterly, 43(2), 271-290.

Hendrix, N. M., Hojnoski, R. L., Missall, K. N. (2018). Promoting numeracy skills through board game play. Young Exceptional Children, 20(10), 1-12. https://doi.org/10.1177/1096250618814239

Henricks, T. S. (2014). Play as self-realization: Toward a general theory of play. American Journal of Play, 6(2), 190-213.

Hsi, K. Y. (2017). A narractive of regaining abundant life: A table-top game teacher encounters with high risk adolescent students. https://ndltd.ncl.edu.tw/cgi-bin/gs32/gsweb.cgi/ccd=d717.N/fulltextdeclare

Jamshed, S. (2014). Qualitative research method-interviewing and observation. Journal of Basic and Clinical Pharmacy, 5(4), 87-88.

Krefting, L. (1991). Rigor in qualitative research: The assessment of trustworthiness. The American Journal of Occupational Therapy, 45(3), 214-222.

Miller, E., \& Almon, J. (2009). Crisis in the kindergarten: Why children need to play in school. Alliance for Childhood.

Mostowfi, S., Mamaghani, N. K., \& Khorramar, M. (2016). Designing playful learning by using educational board game for children in the age range of 7-12 (A case study: Recycling and waste separation education board game). International Journal of Environmental and Science Education, 11(12), 5453-5476.

Nicholson, S. (2008). Modern board games: It's not a Monopoly any more. Library Technology Reports, 44(3), $8-10$.

Nicolopoulou, A. (2010). The alarming disappearance of play from early childhood education. Human Development, 53(1), 1-4. https://doi.org/10.1159/000268135

Paris, T. N. S. T. D., \& Yussof, R. L. (2013). Use of 'time trap board game' to teach grammar. Procedia-Social and Behavioural Sciences, 105, 398-409.

Paris, T. N. S. T., \& Yussof, R. L. (2012). Enhancing grammar using board game. Procedia-Social and Behavioral Sciences, 68, 213-221. https://doi.org/10.1016/j.sbspro. 2012.12.221

Parmar, P., Harkness, S., \& Super, C. M. (2004). Asian and Euro-American parents' ethnotheories of play and learning: Effects on preschool children's home routines and school behaviour. International Journal of Behavioral Development, 28(2), 97-104. https://doi.org/10.1080/01650250344000307

Ramani, G. B., Siegler, R. S., \& Hitti, A. (2012). Taking it to the classroom: Number board games as a small group learning activity. Journal of Educational Psychology, 104(3), 661-672. https://doi.org/10.1037/a0028995

Sato, A., \& de Haan, J. (2016). Applying an experiential learning model to the teaching of gateway strategy

70 Consortia Academia Publishing (A partner of Network of Professional Researchers and Educators) 
board games. International Journal of Instruction, 9(1), 3-16.

Schaefer, C. E., and Reid, S. E. (2001). Game play: Therapeutic use of childhood games. John Wiley and Sons.

Sherwood, Sara. A., \& Reifel, S. (2010). The multiple meanings of play: Exploring preservice teachers' beliefs about a central element of early childhood education. Journal of Early Childhood Teacher Education, 31(4), 322-343. https://doi.org/10.1080/10901027.2010.524065

Sung, H.-C., \& Ching, G. S. (2012, April). A case study on the potentials of card game assisted learning. International Journal of Research Studies in Educational Technology, 1(1), 25-31. https://doi.org/10.5861/ijrset.2012.v1i1.64

Wang, Z., \& Hung, L. M. (2010). Kindergarten children's number sense development through board games. International Journal of Learning, 17(8), 19-31.

Whittam, A. M., Chow, W. (2017). An educational board game for learning and teaching burn care: A preliminary evaluation. Scars, Burns \& Healing, 3. https://doi.org/10.1177/205951311690012

Woods, S. (2012). Eurogames: The design, culture and play of modern European board games. McFarland. 
Jang, L.-F., \& Tan, W. G.

72 Consortia Academia Publishing (A partner of Network of Professional Researchers and Educators) 